\title{
A Semiochemical Slow-release Formulation in a Biological Control Approach to Attract Hoverflies
}

\author{
Stéphanie Heuskin(Corresponding author) \\ Laboratory of Analytical Chemistry \\ Department Analysis, Quality and Risk \& Department of General and Organic \\ Chemistry, Gembloux Agro-Bio Tech, University of Liege, Passage des Déportés 2 \\ B-5030 Gembloux, Belgium
}

Tel: 32-8162-2218 Fax: 3281622216 E-mail: stephanie.heuskin@ulg.ac.be

Stéphanie Lorge, Georges Lognay

Laboratory of Analytical Chemistry, Department Analysis, Quality and Risk

Gembloux Agro-Bio Tech, University of Liege

Passage des Déportés 2, B-5030 Gembloux, Belgium

E-mail: stephanie.lorge@ulg.ac.be/georges.lognay@ulg.ac.be

Jean-Paul Wathelet

Department of General and Organic Chemistry

Gembloux Agro-Bio Tech, University of Liege

Passage des Déportés 2, B-5030 Gembloux, Belgium

E-mail: jp.wathelet@ulg.ac.be

François Béra

Department of Food Processing Industry

Gembloux Agro-Bio Tech, University of Liege

Passage des Déportés 2, B-5030 Gembloux, Belgium

E-mail: f.bera@ulg.ac.be 
Pascal Leroy, Eric Haubruge

Department of Functional and Evolutionary Entomology

Gembloux Agro-Bio Tech, University of Liege

Passage des Déportés 2, B-5030 Gembloux, Belgium

E-mail: p.leroy@ulg.ac.be/e.haubruge@ulg.ac.be

\author{
Yves Brostaux \\ Department of Statistics, Mathematics and Applied Computer Sciences \\ Gembloux Agro-Bio Tech, University of Liege \\ Passage des Déportés 2, B-5030 Gembloux, Belgium \\ E-mail: y.brostaux@ulg.ac.be
}

Received: Apirl 27, 2012 Accepted: May 2, 2012 Published: December 1, 2012

doi:10.5296/jee.v3i1.1725 URL: http://dx.doi.org/10.5296/jee.v3i1.1725

\begin{abstract}
$E$ - $\beta$-Farnesene, the alarm pheromone of many aphid species, and $E$ - $\beta$-caryophyllene are considered as two sesquiterpenes attractive for aphid predators, among which Syrphidae species. Both compounds were formulated in alginate gel beads as slow-release devices in a biological control approach against aphids. Semiochemical diffusion from beads was studied in the laboratory according to abiotic parameters. Efficiency of formulations as hoverfly attractant was demonstrated in field experiments from June to August 2009.

The diffusion of semiochemicals from alginate bead formulations was principally limited by high values $(>85 \%)$ of relative humidity in the air. Temperature also impacts the release of volatile compounds. In field experiments, these two abiotic factors were supposed to highly condition the trapping of hoverflies. These field trappings demonstrated the efficiency of both semiochemical formulations compared to control (formulation without semiochemical) to catch females of Syrphidae during three months.
\end{abstract}

This research proved the efficiency of semiochemical alginate formulations as potential biological control tool to attract aphid predators.

Keywords: Semiochemical, Sesquiterpene, Hoverfly, Aphid, Alginate, Controlled-release, Pest management 


\section{Introduction}

Biological control is an integrated pest management (IPM) strategy which consists in using living organisms (insect predators or parasitoids, pathogens) to suppress pest populations, making them less damaging that they would otherwise be (Stoner, 2004). IPM programs are increasing since the emergence of environmental side effects and risks for human health with the use of synthetic pesticides. Furthermore, development of pest resistance towards synthetic pesticides was related (Foster et al., 2005), as well as no species-specificity of pesticides with lethal effects on beneficial insects (Moens et al., 2010).

Hoverfly larvae (Diptera: Syrphidae) are considered since many years as one of the most important predator of aphids. Already in 1985 and 1986, Chambers et al (Chambers et al., 1985, 1986) reported the economic importance of hoverfly species as aphidophagous biological control agents. Other studies highlighted the role of volatile compounds - coming from aphid-damaged plants and from aphids themselves - as semiochemical cues in the foraging process of female Syrphidae (Almohamad et al., 2006; Harmel et al., 2007). Among these molecules, $E$ - $\beta$-farnesene, the alarm pheromone of many aphid species (Francis et al., 2005a), was largely implicated in oviposition induction of Syrphidae (Francis et al., 2005b; Verheggen et al., 2008, 2009, 2010).

In the current study, $E$ - $\beta$-farnesene and $E$ - $\beta$-caryophyllene, another sesquiterpene compound having interesting biological properties (aggregation pheromone of the Asian ladybeetle, Harmonia axyridis Pallas (Brown et al., 2006; Verheggen et al., 2007) and reducer of aphid reproduction (Tomova et al., 2005), were formulated in slow-release devices. The efficiency of such devices was demonstrated in terms of semiochemical slow-release according to abiotic factors and in terms of attraction of female Syrphidae during field-trials.

In respect with biological control approaches, environmentally safe materials were considered. First of all, volatile organic compounds were extracted and purified from essential oils of Matricaria chamomilla L. (Asteraceae) and Nepeta cataria L. (Lamiaceae) for $E$ - $\beta$-farnesene and $E$ - $\beta$-caryophyllene, respectively (Heuskin et al., 2009, 2010). Secondly, alginate biodegradable matrix was chosen to formulate semiochemicals. This polysaccharide having low oxygen permeability can protect the sesquiterpenes from oxidation. The protection efficiency of alginate beads towards both molecules was demonstrated in Heuskin et al. (2010). This formulation was optimised in terms of semiochemical encapsulation capacity and already proved its biological efficiency by attracting aphid parasitoids, Aphidius ervi (Heuskin et al., 2012).

\section{Material and Methods}

\subsection{Chemicals and Reagents}

Chemicals and reagents ( $E$ - $\beta$-farnesene, $E$ - $\beta$-caryophyllene, (+)-Longifolene) used in this research were the same than presented in a previous paper (Heuskin et al., 2012).

$n$-Hexane of GC grade was purchased from VWR (Leuven, Belgium). $n$-Pentane extra pure was purchased from Acros Organics (Geel, Belgium). 
Sodium alginate (Sigma No. A-2158; Mannuronate/Guluronate: 1.56; Molar mass: 235.5) and $\alpha$-tocopherol used in bead formulations were purchased from Sigma-Aldrich (Bornem, Belgium). Calcium chloride was purchased from Acros Organics (Geel, Belgium).

\subsection{Alginate Bead Formulation}

Alginate bead formulation was optimised in a previous study (Heuskin et al., 2012), in terms of semiochemical formulation efficiency.

The experimental conditions are described hereafter. Sodium alginate solution was prepared in distilled water at $1.5 \% \mathrm{w} / \mathrm{v}$. Calcium chloride solution was prepared in distilled water at a concentration of $0.2 \mathrm{M}$ in such a way the ionic strength of this $\mathrm{CaCl}_{2}$ solution was $0.5 \mathrm{M}$. Eight $\mathrm{mL}$ of sodium alginate solution added to $1.8 \mathrm{~mL}$ sunflower oil, $150 \mathrm{mg} \alpha$-tocopherol as antioxidant and $0.2 \mathrm{~g}(2 \% \mathrm{w} / \mathrm{v}) E$ - $\beta$-caryophyllene or $0.6 \mathrm{~g}(6 \% \mathrm{w} / \mathrm{v}) E$ - $\beta$-farnesene (from essential oil fractionations) were mixed with an ultraturax system (IKA T18 Basic, QLab, Vilvoorde, Belgium) at $24000 \mathrm{rpm}$ during 20 seconds to obtain a thin and homogeneous emulsion. The emulsion was extruded by needle $(0.4 \mathrm{~mm}$ I.D.) and droplets fell into agitated (magnetic stir bar at $600 \mathrm{rpm}$ ) $\mathrm{CaCl}_{2}$ solution to form the alginate gel beads containing semiochemical components. The distance between needle and chloride solution was fixed at $20 \mathrm{~cm}$ to obtain spherical beads. The beads stayed 48 hours in the ionic solution to stabilise the syneresis phenomenon. In order to eliminate surface water, beads were dried before use. They were first drained off on a filter paper during a few seconds. Then they were dried under air pressure at 2 bars during 30 minutes at $21^{\circ} \mathrm{C} \pm 2{ }^{\circ} \mathrm{C}$.

\subsection{Slow-release Measurement}

The collection system dedicated to the measure of volatile compounds consisted in double Teflon funnel-shaped devices (Isoflon, Diemoz, France) containing slow-release formulations (200 mg semiochemical alginate beads) deposited side by side on a sintered surface. An air generator pulled the air to diffuse in a bottle with supersaturated saline solution. Saline solutions were used to fix relative humidity $(\mathrm{RH})$ at different values (in \%) (distilled water: 100\%; $\mathrm{BaCl}_{2}$ : 90\%; $\mathrm{KCl}: 85 \%$; $\mathrm{NaCl}: 75 \%$; $\left.\mathrm{CH}_{3} \mathrm{COOK}: 25 \%\right)$ in the sampling system. Airflow adjusted from $0.05 \mathrm{~L} / \mathrm{min}$ to $1.00 \mathrm{~L} / \mathrm{min}$ was checked every day with an airflow meter.

The volatile compounds released by the alginate formulations were retained on two traps (collection and security traps). The traps consisted in $60 \mathrm{mg}$ of HayeSep Q 80-100 mesh (Alltech, Lokeren, Belgium) packed in Teflon tubing (4 mm I.D. x $1 \mathrm{~mm}$ wall thickness) between 2 pieces of inox (AISI 304) wire cloth of 325 mesh (Haver Belgium S.A., Battice, Belgium) and 2 glass tubing (4 mm O.D. x $0.8 \mathrm{~mm}$ wall thickness). Volatile collection was running 24 hours a day. During that period no breakthrough of the tested molecules was observed. The system was only switched off during the change of trap cartridges every day (less than $5 \mathrm{~min}$ ). All tubing connections were made in Teflon. The volatile collection system was completely included in a thermally controlled room (Maxi Artic Jouan, Vel, Louvain-la-Neuve, Belgium) programmed at $20{ }^{\circ} \mathrm{C}$ or $40{ }^{\circ} \mathrm{C}\left( \pm 1{ }^{\circ} \mathrm{C}\right)$. Temperature and 
relative humidity were continuously recorded during all the duration of the experiments by means of a Hobo data logger (Miravox, Hoevenen, Belgium).

After volatile sampling, each trap (collection and security traps) was eluted 4 times with 250 $\mu \mathrm{L} n$-hexane. Twenty microlitres of internal standard (longifolene) at $1 \mu \mathrm{g}^{-1}$ in $n$-hexane were added at each elution sample before analysis and quantification by fast GC.

\subsection{Fast GC Analyses}

Sesquiterpene analyses and quantification of volatile collection extracts by fast GC were validated according to the accuracy profile procedure described in Heuskin et al. (2010) with longifolene as internal standard for quantification. The chromatographic conditions are the same than the one previously detailed in previous papers (Heuskin et al., 2009, 2010, 2012).

\subsection{Field Experiments}

Field experiments were conducted to estimate the attraction efficiency of semiochemical formulations on hoverflies. These experiments were run from June to August 2009 on three no pesticide-treated crop fields (beet, horse bean, winter wheat) of the University of Liege, Gembloux Agro-Bio Tech in Gembloux (Belgium). The following experimental conditions were investigated. One experimental plot (latin square design) was delineated in each crop at the $20 \times 60 \mathrm{~m}$ dimensions. Two formulations ( $E$ - $\beta$-farnesene and $E$ - $\beta$-caryophyllene alginate beads) and a control (alginate beads without semiochemical) were tested and replicated three times in a plot. Two hundreds mg of formulations were deposited in sticky delta traps (Pirlot, Waremme, Belgium). Distances between traps were of $10 \mathrm{~m}$ and $30 \mathrm{~m}$ for the lines and the columns of the latin square design, in respect with one replicate of each formulation per line and per column.

In order to evaluate the biological efficiency of formulations, the number of female hoverflies in each trap was recorded. In the same time the size of aphid populations nearby each trap (in an area of $1 \mathrm{~m}$ around the trap) was approximated to statistically determine the effect of formulations or aphids on the hoverfly attraction.

The weather conditions (temperature and relative humidity) were recorded during all the duration of experiments by means of a Hobo data logger (Miravox, Hoevenen, Belgium). The data with means, standard deviation (SD), minimal and maximal values, are presented in Table 1. 


\section{Macrothink}

Table 1. Weather conditions from June to August 2009 presented with means, standard deviations, minimum and maximum values of temperature $\left({ }^{\circ} \mathrm{C}\right)$ and relative humidity $(\%)$.

\begin{tabular}{lllll}
\hline & Mean & SD & Min. value & Max. value \\
\hline Temperature $\left({ }^{\circ} \mathrm{C}\right)$ & 20.9 & 8.4 & 3.3 & 41.9 \\
Relative humidity $(\%)$ & 63.1 & 24.5 & 23.6 & 100.0 \\
\hline
\end{tabular}

\subsection{Data Analysis}

Data were presented as total number of female hoverflies caught per formulation and per crop from June to August 2009. Data were subjected to one-way or two-way analysis of covariance (ANCOVA) followed by a Dunnett's test (95\%) (comparison with a control) to compare the trap data observed for the two semiochemical formulations to the control. The influence of covariates was tested: lines and columns of the latin square plot, and aphid population size in $1 \mathrm{~m}$ around the traps. Aphid population size was estimated for all the duration of experiments and was reported in classes according to the density of aphids (class 1: < 5 aphids; class 2: from 5 to 50 aphids; class 3: from 50 to 500 aphids; class 4: > 500 aphids). All statistical analyses were conducted by using Minitab v15 for Windows ${ }^{\circ}$

\section{Results}

\subsection{Semiochemical Release Rate Measurements}

Semiochemical release rates were measured at various experimental conditions (Table 2) in order to evaluate the impact of abiotic factors (temperature, relative humidity, sampling airflow) on the diffusion process of sesquiterpenes from alginate formulations. In each case, diffusion coefficient was estimated according to the theoretical equation for the diffusion in a sphere (Cranck, 1975):

$$
\frac{M_{t}}{M_{\infty}}=1-\frac{6}{\pi^{2}} \sum_{n=1}^{\infty} \frac{1}{n^{2}} \exp \left(-D n^{2} \pi^{2} t / a ?\right.
$$

where $M_{t}$ (in $\mu \mathrm{g}$ ) is the cumulative quantity of semiochemical released at time $t, M_{\infty}$ (in $\mu \mathrm{g}$ ) is the cumulative quantity of semiochemical released at time $\infty$ (supposed to be the total quantity of semiochemical incorporated in the bead at time $\mathrm{t}=0$ ), $a$ (in $\mathrm{m}$ ) is the radius of one bead; $t$ (in s) is the diffusion time; $n$ is the number of terms in the sum and $D$ (in $\mathrm{m}^{2} / \mathrm{s}$ ) is the effective diffusion coefficient. The previous equation was applied according to the following assumptions: (i) diffusion was realised in a non-steady state, (ii) the semiochemical surface 
concentration was considered constant over time, (iii) the radius of the bead was assumed to be constant over time. In practice, diffusion coefficient was approximated at the value which minimised the sum square (SS) between the experimental and the theoretical $M_{t} / M_{\infty}$ values, by using the solver tool in Excel (v. 2003). In each experimental test, $M_{\infty}$ was noticed at 8160 $\mu \mathrm{g} / 200 \mathrm{mg}$ alginate beads and $7600 \mu \mathrm{g} / 200 \mathrm{mg}$ alginate beads for $E$ - $\beta$-farnesene and $E$ - $\beta$-caryophyllene, respectively. These values were found in a previous study (Heuskin et al., 2012).

Figures $1 \mathrm{a}$ and $1 \mathrm{~b}$ show the cumulative release rates over time for the eight experiments for $E$ - $\beta$-farnesene and $E$ - $\beta$-caryophyllene, respectively. Calculated diffusion coefficients are presented in Table 2 for both molecules.

Table 2. Laboratory experimental conditions to determine release rates and diffusion coefficients for $E$ - $\beta$-farnesene and $E$ - $\beta$-caryophyllene.

\begin{tabular}{llllll}
\hline Experimental & $\begin{array}{l}\text { Relative } \\
\text { humidity }\end{array}$ & Airflow & Temperature & $\begin{array}{l}\text { Diffusion } \\
\text { coefficient }\end{array}$ & $\begin{array}{l}\text { Diffusion } \\
\text { coefficient for } E \text { - } \\
\text { test }\end{array}$ \\
$(\%)$ & $(\mathrm{L} / \mathrm{min})$ & $\left({ }^{\circ} \mathrm{C}\right)$ & -caryophyllene \\
& & & & for $E$ - $\beta$-farnesene & $\begin{array}{l}\beta \text {-cille } \\
\left(\mathrm{m}^{2} / \mathrm{s}\right)\end{array}$ \\
\hline
\end{tabular}

$\begin{array}{lccccc}\mathrm{N}^{\circ} 1 & 25 & 0.05 & 20 & 1.98 * 10^{-14} & 1.35 * 10^{-15} \\ \mathrm{~N}^{\circ} 2 & 25 & 0.50 & 20 & 3.40 * 10^{-14} & 1.57 * 10^{-15} \\ \mathrm{~N}^{\circ} 3 & 25 & 1.00 & 20 & 3.71 * 10^{-14} & 1.23 * 10^{-15} \\ \mathrm{~N}^{\circ} 4 & 75 & 0.50 & 20 & 1.23 * 10^{-14} & 7.39 * 10^{-15} \\ \mathrm{~N}^{\circ} 5 & 75 & 0.50 & 40 & 2.12 * 10^{-14} & 1.03 * 10^{-14} \\ \mathrm{~N}^{\circ} 6 & 85 & 0.50 & 20 & 1.56 * 10^{-15} & 1.33 * 10^{-32} \\ \mathrm{~N}^{\circ} 7 & 90 & 0.50 & 20 & 6.15 * 10^{-33} & 8.26 * 10^{-33} \\ \mathrm{~N}^{\circ} 8 & 100 & 0.50 & 20 & 1.03 * 10^{-32} & 9.93 * 10^{-31}\end{array}$




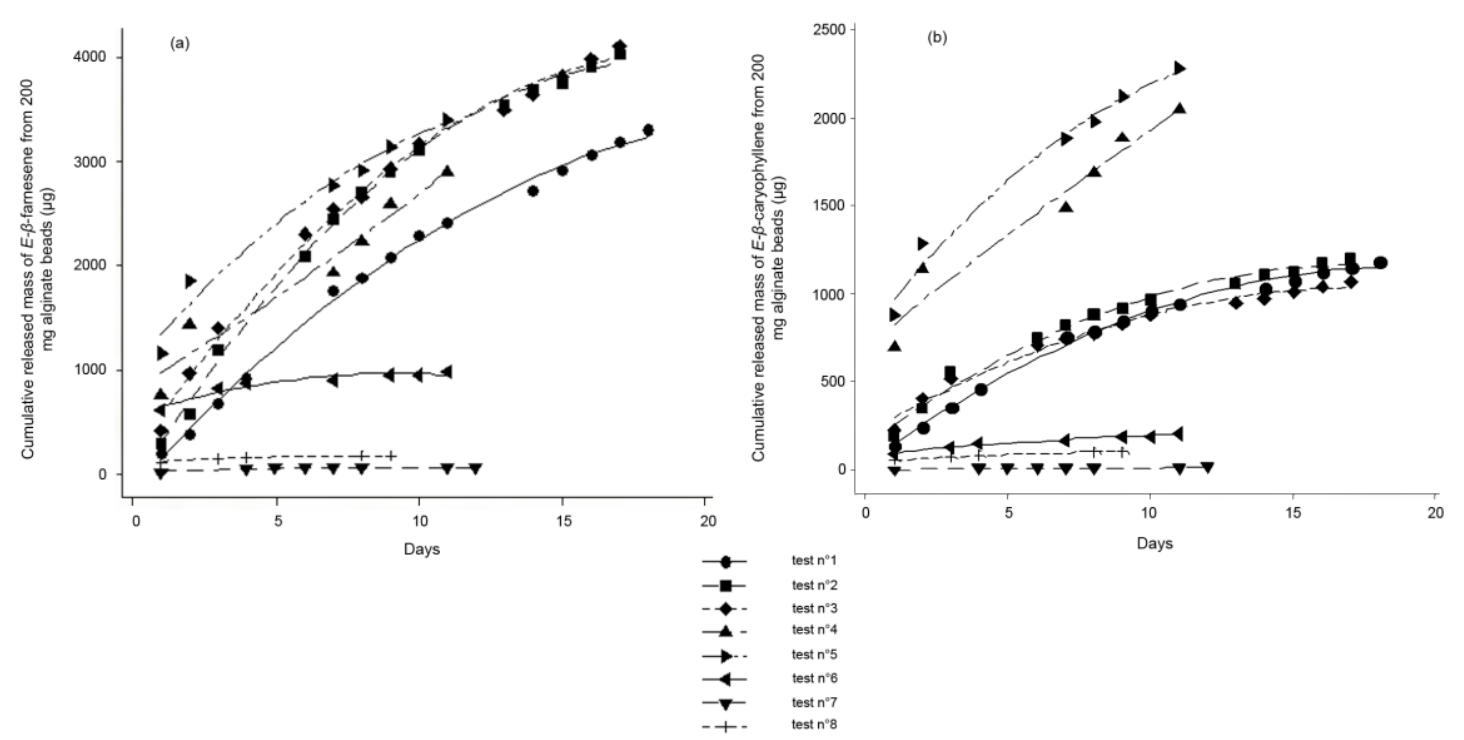

Figure 1. Cumulative mass released (in $\mu \mathrm{g}$ ) of semiochemical (E- $\beta$-farnesene (a) and E- $\beta$-caryophyllene (b)) from alginate beads $(200 \mathrm{mg})$ under eight different experimental conditions.

Considering release graphs and diffusion coefficients obtained for both molecules, the most limiting abiotic factor on release kinetic was the relative humidity (comparison of tests $\mathrm{n}{ }^{\circ} 2$, $4,6,7$ and 8 ). Indeed, from $85 \%$ to $100 \%$ relative humidity, semiochemical releases decreased for $E$ - $\beta$-farnesene and $E$ - $\beta$-caryophyllene with diffusion coefficients close to zero $\left(10^{-31}-10^{-33}\right)$ after 10 days. It was assumed that water absorbed by alginate created a physical barrier to semiochemical diffusion. At lower relative humidities, diffusion behaviours were not the same for both compounds. In the case of $E$ - $\beta$-caryophyllene, tests led at $75 \%$ relative humidity gave higher release quantities and higher diffusion coefficients than at $25 \%$. For $E$ - $\beta$-farnesene, release values (cumulative quantity and diffusion coefficients) were in the same range for $25 \%$ and $75 \%$ relative humidity.

On field, relative humidity was subjected to high variations from day to day, alginate beads suffering from cyclic water absorption and desorption. In order to verify the release efficiency of such beads, a complementary laboratory study consisted in applying from 1 to 4 water absorption - desorption cycles to beads and to measure release during 10 days after each cycle. As presented in Table 3, diffusion coefficients were not highly influenced by multiple water absorption and desorption phenomena. 
Table 3. Diffusion coefficients of $E$ - $\beta$-farnesene and $E$ - $\beta$-caryophyllene obtained after 1 to 4 water absorption-desorption cycles.

\begin{tabular}{lll}
\hline Number of cycle & $\begin{array}{l}\text { Diffusion coefficient } \\
\text { for } E \text { - } \beta \text {-farnesene } \\
\left(\mathrm{m}^{2} / \mathrm{s}\right)\end{array}$ & $\begin{array}{l}\text { Diffusion coefficient } \\
\text { for } E \text { - } \\
\beta \text {-caryophyllene } \\
\left(\mathrm{m}^{2} / \mathrm{s}\right)\end{array}$ \\
\hline & & \\
1 & $1.23 * 10^{-14}$ & $7.39 * 10^{-15}$ \\
2 & $2.74 * 10^{-14}$ & $9.88 * 10^{-15}$ \\
3 & $3.94 * 10^{-15}$ & $2.10 * 10^{-15}$ \\
4 & $1.43 * 10^{-14}$ & $1.25 * 10^{-15}$ \\
\hline
\end{tabular}

The second abiotic parameter which seemed to impact semiochemical diffusion was the temperature. Two temperatures were laboratory-tested: $20^{\circ} \mathrm{C}$ and $40{ }^{\circ} \mathrm{C}$ (tests $\mathrm{n}^{\circ} 4$ and 5). As expected with the literature (Van der Kraan et al., 1990; Torr et al., 1997; Atterholt et al., 1999; Johansson et al., 2001; Cork et al., 2008; Shem et al., 2009), release rates increased at higher temperature for the two sesquiterpenes. Temperature had a direct impact on the rate of evaporation of molecules in the air (Krüger et al., 2002).

The last tested factor to estimate release was sampling airflow. Compared to the two other parameters (temperature and relative humidity), airflow had very few influence on diffusion kinetic. Three airflow values $(0.05,0.50$ and $1.00 \mathrm{~L} / \mathrm{min})$ (tests $\mathrm{n}^{\circ} 1,2$ and 3 ) were evaluated in the release study. With $E$ - $\beta$-caryophyllene formulation, cumulative released masses and diffusion coefficients were approximately the same for the three airflow values. In the case of $E$ - $\beta$-farnesene, airflow at $0.05 \mathrm{~L} / \mathrm{min}$ led to a lowest released quantity of semiochemical than at 0.50 and $1.00 \mathrm{~L} / \mathrm{min}$.

As shown in this study, temperature and relative humidity factors were of significant importance in the efficiency of semiochemical release from alginate beads. In field experiments, these two climatic parameters were supposed to highly condition the trapping of Syrphidae from day to day.

\subsection{Field-trapping Experiments}

Bioassay results with statistical values are presented in Table 4 with mean numbers $( \pm$ SD) of female Syrphidae captured per formulation for each crop and for the three crops. In each case, influence of covariates (lines and columns of the latin square plot, and aphid population size) was statistically evaluated. Lines and columns had no significant influence (p-values >0.05) on the attraction of hoverflies. On the other hand, aphid population size significantly influenced the catches with p-values of $0.0500,0.0040$ and 0.0010 for beet, horse bean and for the global data (3 crops), respectively. No aphid influence was shown for wheat, aphid population density being the same (class 1) for each trap of the crop.

Dunnett's test results showed differences of hoverfly attraction between formulations and control, and between crops after aphid influence subtraction (adjusted p-values). In beet crop, 
only $E$ - $\beta$-caryophyllene formulation was highly significantly different compared to the control $(\mathrm{p}$-value $=0.0011)$. On the other hand, in horse bean crop, only $E$ - $\beta$-farnesene differed from the control $(\mathrm{p}$-value $=0.0052)$. In wheat field, both formulations were not different from the control in terms of attraction. In order to reduce the differences observed between crops, the three crops were treated in the same statistical analysis. By considering the globality of experiments (for 3 crops), both $E$ - $\beta$-farnesene and $E$ - $\beta$-caryophyllene were significantly different from the empty alginate beads (control) with adjusted p-values of 0.0416 and 0.0064 , respectively.

Table 4. Catches of female Syrphidae (mean \pm SD) per formulation and per crop with the statistical data

\begin{tabular}{|c|c|c|c|c|}
\hline & Beet & Horse Bean & Wheat & $\begin{array}{l}\text { Global data } \\
\text { (3 crops) }\end{array}$ \\
\hline Mean \pm SD Control & $45.6 \pm 7.6$ & $78.3 \pm 11.6$ & $\begin{array}{l}27.0 \pm \\
12.3\end{array}$ & $\begin{array}{l}50.3 \pm \\
24.3\end{array}$ \\
\hline Mean \pm SD $E$ - $\beta$-farnesene & $76.0 \pm 36.4$ & $139.7 \pm 29.8$ & $\begin{array}{l}40.0 \pm \\
14.8\end{array}$ & $\begin{array}{l}85.2 \pm \\
50.2\end{array}$ \\
\hline Mean \pm SD $E$ - $\beta$-caryophyllene & $\begin{array}{l}145.7 \pm \\
13.5\end{array}$ & $91.0 \pm 31.4$ & $38.3 \pm 8.7$ & $\begin{array}{l}91.7 \pm \\
49.7\end{array}$ \\
\hline $\begin{array}{l}\text { Aphid influence (p-value) } \\
\text { Dunnett's test (Adjusted } \\
\text { p-value) }\end{array}$ & 0.0500 & 0.0040 & I & 0.0010 \\
\hline$E$ - $\beta$-farnesene & 0.0513 & $0.0052^{* *}$ & 0.3796 & $0.0416^{*}$ \\
\hline$E$ - $\beta$-caryophyllene & $0.0011^{* *}$ & 0.1723 & 0.4621 & $0.0064^{* *}$ \\
\hline
\end{tabular}

\footnotetext{
Significant difference compared to the control

** High significant difference compared to the control
}

These results demonstrated the effective and sufficient release of volatile compounds during the period of experiment. Indeed, as shown in Table 1, mean relative humidity value was $63.1 \%$. That is in the optimal releasing conditions as demonstrated in paragraph 3.1.

\section{Discussion and Conclusion}

Adult hoverflies are considered as important pollinators of flowering plants given that they feed on nectar and pollen. On the other hand, larvae are one of the most important aphid predators (Ghalari et al., 2008). Some studies demonstrated the attraction of adult hoverfly species by means of selected flowering plants established close to crop fields in order to reduce aphid population size after females have laid their eggs (Ambrosino et al., 2006; Sadeghi, 2008). Sadeghi (2008) showed the higher Syrphidae attractiveness with Matricaria chamomilla flowering plant. 
In the present research, the bioassay results were in accordance with previous works (Almohamad et al., 2006; Harmel et al., 2007) showing the attraction efficiency of $E$ - $\beta$-farnesene towards hoverflies. Nevertheless, these previous studies dealt with the use of synthetic pheromones as attractant contrarily to the current work where semiochemicals from natural origin were used. In the case of $E$ - $\beta$-caryophyllene, the attraction phenomenon was higher than for $E$ - $\beta$-farnesene. Furthermore, to our knowledge, it was the first time this molecule was tested as a potential attractant of hoverflies. Nevertheless, $E$ - $\beta$-caryophyllene was already demonstrated to be attractive towards aphid parasitoids, Aphidius ervi Haliday (Sasso et al., 2009). The attraction efficiency of this compound, found in the volatile blend of tomato plants, was shown by electroantennography and wind tunnel bioassays.

Many semiochemical slow-release devices were reported in the literature, principally as mating disruption systems. These releasers generally consist in solid matrix (polymer) dispensers through which semiochemicals can release over time (Mc Donough et al., 1991; Torr et al., 1997; Johansson et al., 2001; Tomaszewska et al., 2005; Zhang et al., 2008). Some sprayable slow-release formulations were also developed in such a way the semiochemical compounds are dissolved in a biodegradable liquid matrix (Atterholt et al., 1999; De Vlieger, 2001; Welter et al., 2005).

Alginate bead release devices, as presented in this paper, consist in a compromise between solid dispensers and liquid formulations given that a liquid (semiochemical and sunflower oil) is enclosed in a solid polymeric network.

In the present research, alginate beads proved their effectiveness as semiochemical slow-release systems on field experiments despite their limitation of use at high relative humidity. A study of semiochemical release in environmental conditions is currently in prospect as well as the understanding of diffusion phenomenon inside alginate bead network according to abiotic factors.

\section{Acknowledgements}

The authors are grateful to Prof. Bernard Bodson from Gembloux Agro-Bio Tech, University of Liege (Phytotechnie des Régions Tempérées) for giving the authorization to realise field experiments on crops.

This research was funded by a Walloon Region Ministry grant (WALEO2: SOLAPHID RW/FUSAGX 061/6287).

\section{References}

Almohamad R., Verheggen F.J., Francis F., \& Haubruge E. (2006). Evaluation of hoverfly Episyrphus balteatus De Geer (Diptera: Syrphidae) oviposition behaviour towards aphid-infested plants using a leaf disc system. Comm. Appl. Biol. Sci. 71/2b, 403-412.

Ambrosino M.D., Luna J.M., Jepson P.C., \& Wratten S.D. (2006). Relative frequencies of visits to selected insectary plants by predatory hoverflies (Diptera: Syrphidae), other beneficial insects and herbivores. J. Environ. Entomol, 35(2), 394-400. http://dx.doi.org/10.1603/0046-225X-35.2.394 
Atterholt C.A., Delwiche M.J., Rice R.E., \& Krochta J.M. (1999). Controlled release of insect sex pheromones from paraffin wax and emulsions. J. Contr. Rel. 57, 233-247. http://dx.doi.org/10.1016/S0168-3659(98)00119-9

Brown A.E., Riddick E.W., Aldrich J.R., \& Holmes W.E. (2006). Identification of (-)- $\beta$-caryophyllene as a gender-specific terpene produced by the multicolored Asian lady beetle. J. Chem. Ecol. 32, 2489-2499. http://dx.doi.org/10.1007/s10886-006-9158-0

Chambers R.J., \& Adams T.H.L. (1986). Quantification of the impact of hoverflies (Diptera: Syrphidae) on cereal aphids in winter wheat: an analysis of field populations. J. Appl. Ecol. 23, 895-904.

Chambers R.J., Sunderland K.D., Stacey D.L., \& Wyatt I.J. (1985). Control of cereal aphids in winter wheat by natural enemies: aphid-specific predators, parasitoids and pathogenic fungi. Ann. Appl. Biol. 108, 219-231. http://dx.doi.org/10.1111/j.1744-7348.1986.tb07644.x

Cork A., De Souza K., Hall D.R., Jones O.T., Casagrande E., Krishnaiah K., \& Syed Z. (2008). Development of a PVC-resin-controlled release formulation for pheromones and use in mating disruption of yellow rice stem borer, Scirpophaga incertulas. Crop Protec, 27, 248-255. http://dx.doi.org/10.1016/j.cropro.2007.05.011

Cranck J. (1975). The mathematics of diffusion. Clarendon Press, Oxford.

De Vlieger J.J. (2001). Development of a sprayable slow-release formulation for the sex pheromone of the Mediterranean corn borer, Sesamia nonagroides. IOBC wprs Bull, 24(2), 101-106.

Foster S.P., Denholm I., Thompson R., Poppy G.M., \& Powell W. (2005). Reduced response of insecticide-resistant aphids and attraction of parasitoids to aphid alarm pheromone; a potential fitness trade-off. Bull. Entomol. Res. 95, 37-46. http://dx.doi.org/10.1079/BER2004336

Francis F., Martin M., Lognay G., \& Haubruge E. (2005b). Role of E- $\beta$-farnesene in systematic aphid prey location by Episyrphus balteatus larvae (Diptera: Syrphidae). Euro. J. Entomol. 102, 431-436.

Francis F., Vandermoten S., Verheggen F., Lognay G., \& Haubruge E. (2005a). Is the E- $\beta$-farnesene only volatile terpenoids in aphids? J. Appl. Entomol, 129, 6-11. http://dx.doi.org/10.1111/j.1439-0418.2005.00925.x

Ghahari H., Hayat R., Tabari M., \& Ostovan H. (2008). Hover flies (Diptera: Syrphidae) from rice fields and around grasslands of Northern Iran. Munis Entomol, Zool. 3, 275-284.

Harmel N., Almohamad R., Fauconnier M.-L., Du Jardin P., Verheggen F., Marlier M., Haubruge E., \& Francis F. (2007). Role of terpenes from aphid-infested potato on searching and oviposition behavior of Episyrphus balteatus. Insect Sci., 14, 57-63. http://dx.doi.org/10.1111/j.1744-7917.2007.00126.x 
Heuskin S., Godin B., Leroy P., Capella Q., Wathelet J.-P., Verheggen F., Haubruge E., \& Lognay G. (2009). Fast gas chromatography characterisation of purified semiochemicals from essential oils of Matricaria chamomilla L. (Asteraceae) and Nepeta cataria L. (Lamiaceae). J. Chrom. A 1216, 2768-2775. http://dx.doi.org/10.1016/j.chroma.2008.09.109

Heuskin S., Lorge S., Godin B., Leroy P., Frère I., Verheggen F., Haubruge E., Wathelet J.-P., Mestdagh M., Hance T., \& Lognay G. (2012). Optimisation of a semiochemical slow-release alginate formulation attractive towards Aphidius ervi Haliday parasitoids. Pest Manag. Sci. 68, 127-136. http://dx.doi.org/10.1002/ps.2234

Heuskin S., Rozet E., Lorge S., Farmakidis J., Hubert Ph., Verheggen F., Haubruge E., Wathelet J.-P., \& Lognay G. (2010). Validation of a fast gas chromatographic method for the study of semiochemical slow release formulations. J. Pharm. Biomed. Anal, 53, 962-972. http://dx.doi.org/10.1016/j.jpba.2010.07.014

Johansson B.G., Anderbrant O., Simandl J., Avtzis N.D., Salvadori C., Hedenström E., Edlund H., \& Högberg H.-E. (2001). Release rates for pine sawly pheromones from two types of dispensers and phenology of Neodiprion sertifer. J. Chem. Ecol., 27, 733-745.

Krüger A.J., \& Tolmay A.T. (2002). Prediction of the release characteristics of alcohols from EVA using a model based on Fick's second law of diffusion. J. Appl. Poly. Sci. 84, 806-813.

McDonough L.M. (1991). Controlled release of insect sex pheromones from a natural rubber substrate. In: Hedin P.A., ed. Naturally Occurring Pest Bioregulators. American Chemical Society, pp. 106-124.

Moens J., De Clercq P., \& Tirry L. (2010). Side effects of pesticides on the larvae of the hoverfly Episyrphus balteatus in the laboratory. Phytoparasitica. http://dx.doi.org/10.1007/s12600-010-0127-3.

Sadeghi H. (2008). Abundance of adult hoverflies (Diptera: Syrphidae) on different flowering plants. Caspian J. Environ. Sci., 6, 47-51.

Sasso R., Iodice L., Woodcock C.M., Pickett J.A., \& Guerrieri E. (2009). Electrophysiological and behavioural responses of Aphidius ervi (Hymenoptera: Braconidae) to tomato plant volatiles. Chemoecology, 19, 195-201. http://dx.doi.org/10.1007/s00049-009-0023-9

Shem P.M., Shiundu P.M., Gikonyo N.K., Ali A.H., \& Saini R.K. (2009). Release kinetics of a synthetic tsetse allomone derived from waterbuck odour from a Tygon silicon dispenser under laboratory and semi field conditions. Amer.-Euras. J. Agric.Environ. Sci, 6(6), 625-636.

Stoner K. Approaches to the biological control of insects, University of Maine, Coop. Ext. Bull. 7144 (2004), (www.umext.maine.edu/onlinepubs/PDFpubs /7144.pdf; accessed 06/07/10). 


\section{Macrothink}

Tomaszewska E., Hebert V.R., Brunner J.F., Jones V.P., Doerr M., \& Hilton R. (2005). Evaluation of pheromone release from commercial mating disruption dispensers. J. Agric. Food Chem, 53, 2399-2405.

Tomova B.S., Waterhouse J.S., \& Boberski J. (2005). The effect of fractionated Tagetes oil volatiles on aphid reproduction. Entomol. Exp. Appl, 115, 153-159. http://dx.doi.org/10.1111/j.1570-7458.2005.00291.x

Torr S.J., Hall D.R., Phelps R.J., \& Vale G.A. (1997). Methods for dispensing odour attractants for tsetse flies (Diptera: Glossinidae). Bull. Entomol. Res, 87, 299-311. http://dx.doi.org/10.1017/S0007485300037251

Van der Kraan C., \& Ebbers A. (1990). Release rates of tetradecen-1-ol acetates from polymeric formulations in relation to temperature and air velocity. J. Chem. Ecol, 16, 1041-1058. http://dx.doi.org/ 10.1007/BF01021009

Verheggen F.J., Arnaud L., Bartram S., Gohy M., \& Haubruge E. (2008). Aphid and plant volatiles induce oviposition in an aphidophagous Hoverfly. J. Chem. Ecol, 34, 301-307.

Verheggen F.J., Fagel Q., Heuskin S., Lognay G., Francis F., \& Haubruge E. (2007). Electrophysiological and behavioral responses of the multicolored asian lady beetle, Harmonia axyridis Pallas, to sesquiterpene semiochemicals. J. Chem. Ecol, 33, 2148-2155.

Verheggen F.J., Haubruge E., \& Mescher M.C. (2010). Alarm pheromones. In Litwack G. (ed.), Pheromones. Elsevier.

Verheggen F.J., Haubruge E., De Moraes C.M., \& Mescher M.C. (2009). Social environment influences aphid reproduction of alarm pheromone. Behav. Ecol, 20, 283-288. http://dx.doi.org/10.1093/beheco/arp009

Welter S.C., Pickel C., Millar J., Cave F., Van Steenwyk R.A., \& Dunley J. (2005). Pheromone mating disruption offers selective management options for key pests. California Agric, 59(1), 16-22.

Zhang A., Kuang L.F., Maisin N., Karumuru B., Hall D.R., Virdiana I., Lambert S., Purung H.B., Wang S., \& Hebbar P. (2008). Activity Evaluation of cocoa pod borer sex pheromone in cacao fields. Environ. Entomol, 37(3), 719-724. 